\title{
Effect on silicon nitride thin films properties at various pressure of R.F. magnetron sputtering
}

\author{
Uzair Majeed $^{\mathrm{a}, \mathrm{b},{ }^{*}}$, Mohd. Kamarulzaki Mustafa, ${ }^{\mathrm{a}, \mathrm{b}}$, Nafarizal Nayan ${ }^{\mathrm{b}}$ \\ ${ }^{a}$ Faculty of Science, Technology and Human Development, Universiti Tun Hussein Onn Malaysia, 86400 UTHM Batu Pahat, Johor, Malaysia \\ ${ }^{b}$ Microelectronics and Nanotechnology - Shamsuddin Centre of Excellence, Universiti Tun Hussein Onn Malaysia, 86400 UTHM Batu Pahat, Johor, \\ Malaysia \\ *Corresponding Author: uzair.majeed@hotmail.com
}

Article history :

Received 22 Sept 2014

Accepted 1 Apr 2015

\section{GRAPHICAL ABSTRACT}

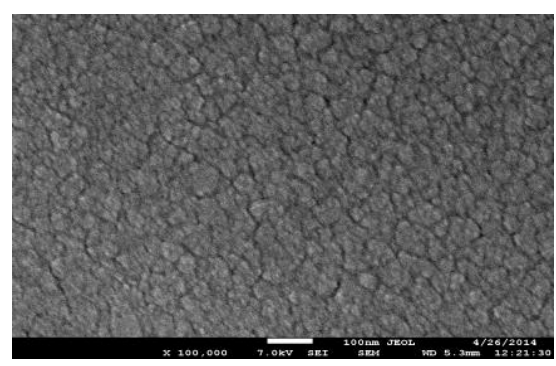

\begin{abstract}
Silicon nitride is a well-known material with numerous applications such as gate dielectrics and etchmasks in semiconductor device fabrication, anti reflective coatings in solar panel manufacturing and optical waveguides in biosensing fields. In this work, silicon nitride thin films were prepared using radio frequency (R.F.) magnetron sputtering technique at room temperature. The properties of thin films were investigated with respect to sputtering-gas pressure during film deposition. The produced thin films were characterized with spectral reflectance, AFM, FTIR and FE-SEM techniques for growth rate, optical properties, surface roughness, morphology, chemical bonding information and surface micro structure. Spectral reflectance results showed that there existed an optimum value of sputteringgas pressure for increase in growth rate and beyond that value the growth rate started decreasing. Refractive index was found to increase with increased pressure which confirmed that the films were Sirich. AFM results revealed that the increment in surface roughness is in direct proportion with working pressure. FTIR results showed the overlapping of $\mathrm{Si}-\mathrm{N}$ and $\mathrm{Si}-\mathrm{O}$ characteristic bands and its shift towards higher wave number due to increasing Si content in deposited films. FE-SEM results showed prominent changes in surface micro structure with higher sputtering-gas pressures.
\end{abstract}

Keywords: R.F. magnetron sputtering, silicon nitride, thin film deposition, pressure, growth rate

(C) 2015 Penerbit UTM Press. All rights reserved http://dx.doi.org/10.11113/mjfas.v11n2.356

\section{INTRODUCTION}

Silicon nitride films are considered very useful for many aspects in material science for their high electrical resistivity, high wear resistance, stability to oxidation in air at high temperatures, and good insulating properties in numerous applications. They have attracted much interest for over two decades for their important applications in microelectronic and optoelectronic industry [1] as gate dielectrics [2], passivation layers [3], Antireflective (AR) coatings [4] and planar optical waveguides [5].

Silicon nitride films are usually deposited through low pressure chemical vapour deposition (LPCVD) [6], plasma enhanced chemical vapour deposition (PECVD) [7] and sputtering [8]. Among these methods, sputtering has been demonstrated to be one of the promising ways to produce the silicon nitride films at a low temperature [9], making this technique as suitable for substrates with low melting point like polymer materials. Moreover, sputtering process avoids toxic gases like silicon hydrochloride $\left(\mathrm{SiH}_{2} \mathrm{Cl}_{2}\right)$ and silicon hydride $\left(\mathrm{SiH}_{4}\right)$ that are inevitable in CVD processes [10]. These toxic gases not only require special handling procedure but also cause hydrogen incorporation into the silicon nitride films. This impurity incorporation could degrade the optical, electronic and mechanical properties of produced thin film [9].

The properties of the silicon nitride thin films are strongly dependent on the sputtering conditions such as substrate temperature, target power, gas flow, target to substrate spacing, deposition time and partial pressure of sputtering gas [11].

In this work, silicon nitride thin films were prepared using RF magnetron sputtering in order to study the effect of various sputtering pressures on the properties of silicon nitride thin films. As there is no gas other than Argon (Ar), therefore the Ar gas pressure is referred here as sputtering pressure.

The produced thin films were characterized for thickness and optical properties, surface roughness, chemical composition and surface microstructure using spectral reflectance (SR) technique, fourier transform infrared (FTIR) spectroscopy, atomic force microscopy (AFM) and field emission - scanning electron microscopy (FE-SEM). 


\section{EXPERIMENTAL DETAILS}

Single sided polished P-type boron doped silicon wafer (with thickness 500um and orientation <100>) were used as substrate. All substrates were cleaned using organic solvents such as acetone and iso propyle alcohol (IPA) for ten minutes in ultrasonic bath. Then the substrate was washed with de-ionized (DI) water $(18 \mathrm{M} \Omega$, Millipore USA) and dried with industrial grade nitrogen gas.

Silicon nitride thin films with an approximate thickness of $250 \mathrm{~nm}$ were deposited using RF magnetron sputtering system (SNTEK, Korea) at room temperature. A stoichiometric $\mathrm{Si}_{3} \mathrm{~N}_{4}$ circular target (Taewon Scientific, Korea) of 3" diameter with thickness 118 " was mechanically clamped to the water cooled R.F. electrode.

The sputtering chamber was evacuated to $4.5 \times 10^{-6}$ Torr to get high purity in thin films. It was achieved from a vacuum turbo molecular pump which was backed by rotary mechanical pump. Argon (Ar) gas with $99.99 \%$ purity was introduced in the chamber as sputtering gas. Ar flow rate was fixed at $15 \mathrm{sccm}$ and power of the system was kept constant at $400 \mathrm{~W}$. Samples were rotated constantly at 7 rpm to improve the film homogeneity. A pre-sputtering process was performed for 10 minutes to clean the sputtering target surface prior to each deposition. At this stage, substrate was covered to avoid any deposition. Experiments were conducted at following sputtering pressures (a) 3 mTorr (b) 6 mTorr (c) 9 mTorr (d) 12 mTorr (e) 15 mTorr. These process parameters are tabulated in Table 1 .

Table 1 Parameters used during sputtering process

\begin{tabular}{|l|l|}
\hline Target & 3 -inch $\mathrm{Si}_{3} \mathrm{~N}_{4}$ target \\
\hline RF power & $400 \mathrm{~W}$ \\
\hline Ar flow rate & $15 \mathrm{sccm}$ \\
\hline Target to substrate spacing & $14 \mathrm{~cm}$ \\
\hline Substrate rotation & $7 \mathrm{rpm}$ \\
\hline Substrate temperature & Room temperature \\
\hline Sputtering pressure & $3,6,9,12,15$ mTorr \\
\hline
\end{tabular}

Thickness and optical properties were measured using spectral reflectance (SR) measurement system (Filmetrics, USA). Surface roughness and morphology were investigated by Atomic force microscopy (AFM) technique (Park system, USA) in non contact mode. Chemical bonding information was acquired by Fourier transform infra red (FTIR) spectroscopy (Perkin Elmer, USA) and microstructures were examined by field emission - scanning electron microscopy (FE-SEM) (Jeol, USA). Growth rate was calculated using the measured thickness divided by deposition time.

\section{RESULTS AND DISCUSSION}

Table 2 shows the growth rate and optical properties of deposited thin films at various pressure values measured using SR technique. The optical properties were investigated at wavelength $\lambda=638.2 \mathrm{~nm}$.

Table 2 Growth rate and optical properties

\begin{tabular}{ccccc}
\hline $\begin{array}{c}\text { Sr. } \\
\text { No }\end{array}$ & $\begin{array}{c}\text { Sputtering } \\
\text { pressure } \\
\text { (mTorr) }\end{array}$ & $\begin{array}{c}\text { Growth } \\
\text { rate } \\
(\mathrm{nm} / \mathrm{min})\end{array}$ & $\begin{array}{c}\text { Refractive } \\
\text { index } \\
\mathrm{n}\end{array}$ & $\begin{array}{c}\text { Extinction } \\
\text { co-efficient } \\
\mathrm{k}\end{array}$ \\
\hline 1 & 3 & 7.0 & 2.09 & 0.05 \\
2 & 6 & 7.6 & 2.11 & 0.05 \\
3 & 9 & 8.5 & 2.16 & 0.04 \\
4 & 12 & 8.0 & 2.30 & 0.03 \\
5 & 15 & 7.6 & 2.53 & 0.03 \\
\hline
\end{tabular}

The measured growth rate was found to increase with lower pressure values. However at optimum pressure value the rate became maximum and beyond that value the growth rate started decreasing, representing the back diffusion of target atoms. Therefore it was observed that for process parameters given in Table 1, sputtering pressure is responsible for a sputtering process until optimum pressure. The shaded area in Figure 1 is the region where sputtering occurred, crossing the value denoted as optimum pressure, back diffusion and scattering started.

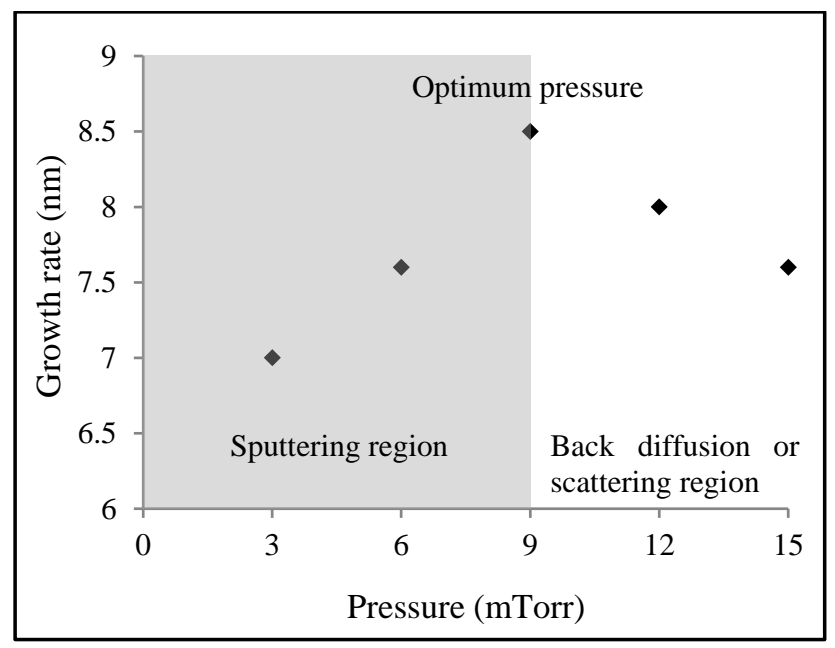

Figure.1 Dependence of growth rate on sputtering pressure

Sputtering is a physical deposition process in which sputtering gas ions strike the sputtering target, transfer their energy to target atoms and eject them from sputtering target. These ejected material travel towards the substrate and settle down there to form a thin film. However, during its travel towards the substrate, target atom encounters many other sputtering gas ions. Therefore the deposition depends on the mean free path $\left(\mathrm{d}_{\mathrm{mfp}}\right)$ of target atom which is mathematically represented [12] as 


$$
\mathrm{d}_{\mathrm{mfp}}=\frac{\mathrm{RT}}{\pi(\mathrm{dc})^{2} \mathrm{~N}_{\mathrm{a}} \mathrm{P}}
$$

where, $\mathrm{R}$ is ideal gas constant, $\mathrm{T}$ is temperature, $\mathrm{d}_{\mathrm{c}}$ is collision diameter of atoms, $\mathrm{N}_{\mathrm{a}}$ is Avogadro's number and $\mathrm{P}$ is sputtering pressure. Assuming all the factors as constant in equation (1) except pressure, shows the inverse relationship between $d_{m f p}$ and sputtering gas pressure. Starting with low pressure values such as 3 mTorr, increase in pressure caused higher growth rate due to more collisions with target atoms. However this growth increase saturated at optimum pressure value ( 9 mTorr in our case). Beyond that value high pressures of Ar ions scattered target atoms result the reduction in growth rate.

The refractive index of stochiometric silicon nitride reported in literature as $\sim 2.0$ [13], however refractive index tuning is possible over a span of 1.47 (silicon dioxide) [10] to 3.5 (silicon rich silicon nitride) [13]. The films obtained in our experiments exhibited a silicon- rich nature. The silicon content increased with sputtering pressure and thus the refractive index. As the refractive index is a function of stochiometry, it is not surprising for deposition from compound target, that stoichiometry of deposited thin film could be different from the target. This happens due to difference in mass of target components and leads to different sputtering yield (S) which is expressed by [14] as,

$$
\mathrm{S}=\frac{3 \alpha}{4 \pi^{2}} \frac{4 \mathrm{~m}_{\mathrm{i}} \mathrm{m}_{\mathrm{t}}}{\left(\mathrm{m}_{\mathrm{i}}+\mathrm{m}_{\mathrm{t}}\right)^{2}} \frac{\mathrm{E}}{\mathrm{U}_{\mathrm{o}}}
$$

where $m_{i}$ and $m_{t}$ are masses of colliding atoms, $U_{o}$ is the surface binding energy of material being sputtered, $\mathrm{E}$ is energy of incident ion, and $\alpha$ is the momentum transfer function. In sputtering process, the target atoms reach at substrate in condensed form and make bond with another atom to become stable. The bond making depends on bonding energy between atoms.

Therefore, if bonding energy in silicon is not sufficient, the nitrogen atom joins another nitrogen atom and evaporates as nitrogen gas. Literature reported the formation of stochiometric films from the stochiometric target when adequate heat is applied to substrate in order to increase the bonding energy [15] and Si-rich silicon nitride films in reactive sputtering at low temperature [9]. The extinction coefficient decreases with the higher pressure values. Extinction coefficient values proved the silicon nitride films are transparent at wavelength $\lambda=638.2 \mathrm{~nm}$.

Surface roughness images were taken by AFM technique in non-contact mode. The scanned area of $3 \mathrm{x}$ $3 \mu \mathrm{m}$ was used for all samples. The root mean square (r.m.s) roughness was calculated with commercial software supplied with the equipment.

Figure 2 shows the surface roughness of deposited thin films as a function of sputtering pressure. The surface roughness was found to increase with high pressure values.
This behavior could be justified as the mobility of target atoms depends on the available kinetic energy $\left(E_{k}\right)$. The high Ek of atoms prevents them to deposit large clusters and thus smooth surfaces are produced [18].

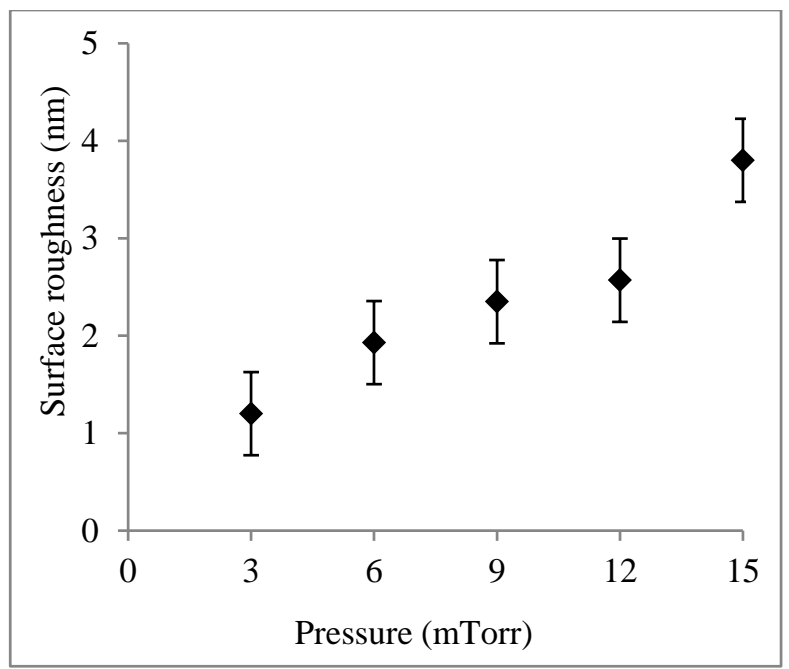

Figure.2 Dependence of surface roughness on sputtering pressure

Literature [19] reported that, at high sputtering pressure, $\mathrm{d}_{\mathrm{mfp}}$ of target atoms reduced while collision probability increased, resulting in loss of their $E_{k}$. Therefore, instead of homogenous arrangement of target material, the clusters formation is observed on substrate with high surface roughness.

Figure 3 shows the surface morphology of thin films. The surfaces are not easily distinguishable due to small differences in surface roughness i.e. in nm. However, the large particle size in Figure 3(e) can be easily found if it is compared with Figure 3(a).

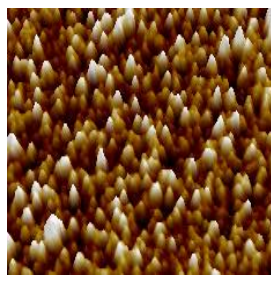

(a)

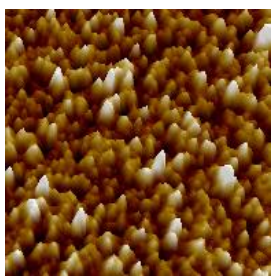

(b)

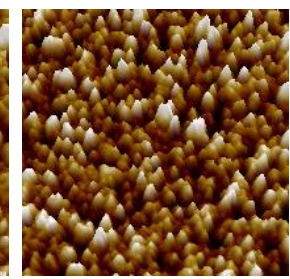

(c)

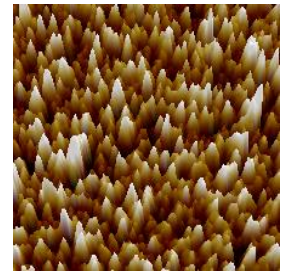

(d)

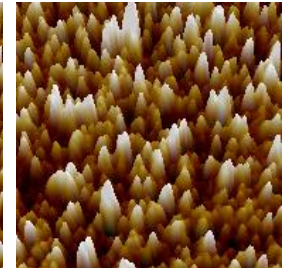

(e)
Figure.3 AFM topographic images at (a) 3 mTorr (b) 6 mTorr (c) 9 mTorr (d) 12 mTorr (e) 15 mTorr 
Figure 4 shows the FTIR spectra of silicon nitride deposition at various sputtering pressures. The spectrum was taken by Perkin Elmer FTIR spectrometer in reflection mode. Reflectivity measurements were carried out in the spectral range $700-4500 \mathrm{~cm}^{-1}$. However as there was no peak after the $1200 \mathrm{~cm}^{-1}$ so the spectrum after $1400 \mathrm{~cm}^{-1}$ was omitted. The band at $830-870 \mathrm{~cm}^{-1}$ are attributed to Si$\mathrm{N}$ [16] while at $1000 \mathrm{~cm}^{-1}$ and above are attributed to $\mathrm{Si}-\mathrm{O}$ [17]. The results demonstrated the overlapping of Si-N and $\mathrm{Si}-\mathrm{O}$ bonding. The replacement of $\mathrm{Si}-\mathrm{N}$ bonding with $\mathrm{Si}-\mathrm{O}$ as the sputtering pressure increased confirmed the excess amount of $\mathrm{Si}$ in deposited thin films. Inset in Figure 3 shows the band maximum shifting towards higher wave number at high sputtering pressure which indicates the inclusion of oxygen into the deposited films.

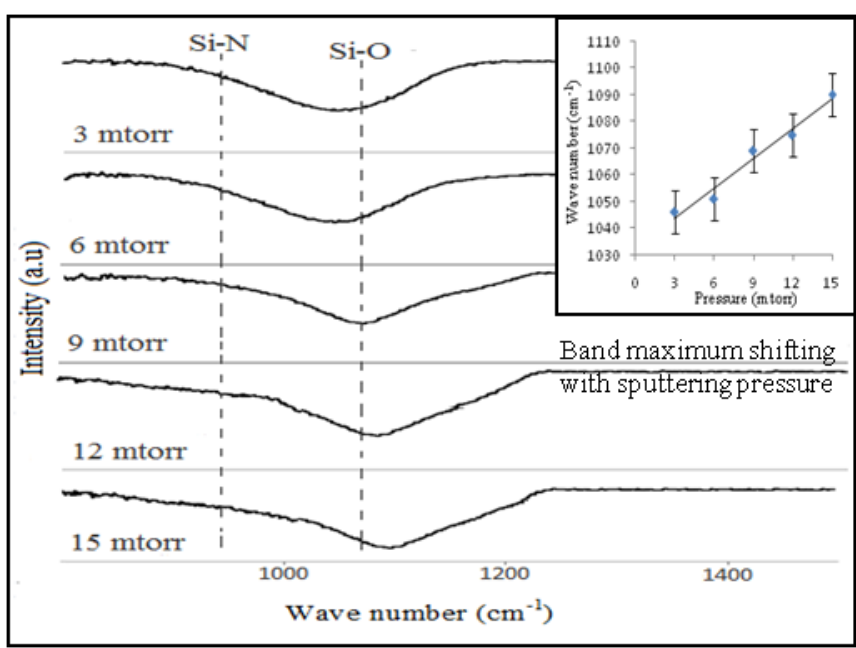

Figure.4 FTIR spectra of silicon nitride thin films at various sputtering pressure

Figure 5 shows the microstructure images of silicon nitride thin films surface observed using FE-SEM at 100,000 magnification and $7 \mathrm{kV}$ acceleration voltages.

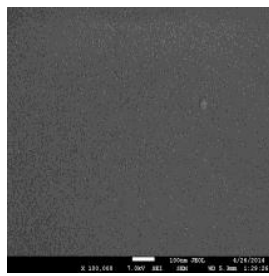

(a)

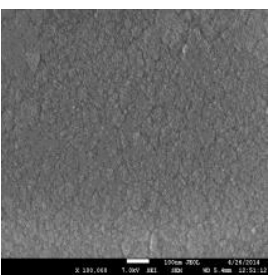

(b)

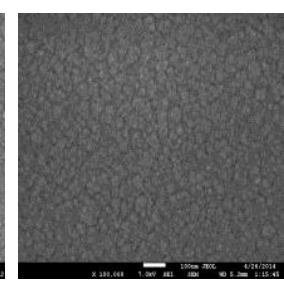

(c)

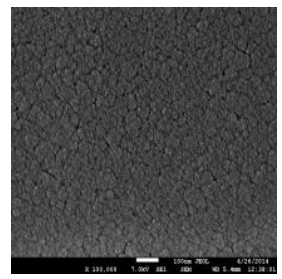

(d)

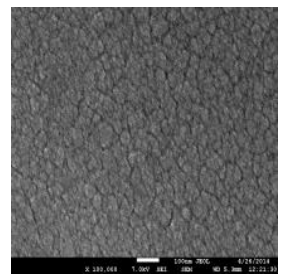

(e)
Figure. 5 FE-SEM microstructure images at (a) 3 mTorr (b) 6 mTorr (c) 9 mTorr (d) 12 mTorr (e) 15 mTorr
Silicon nitride thin film deposited at 3 mTorr was highly dense and more homogenous as compared to film deposited at 15 mTorr. The prominent voids with the increase in sputtering pressure evidence of stress induced in films. This stress could be attributed to $\mathrm{Si}$ dangling bonds or large grain size of deposited material. Both are function of sputtering pressure and having a direct relationship. Therefore experimental studies suggest the deposition at low sputtering pressure in order to avoid the stress induced in thin films.

\section{CONCLUSION}

Silicon Nitride thin films were deposited using a commercial RF magnetron sputtering system following the non reactive sputtering routine. The influence of sputtering pressure was investigated on films ' properties like growth rate, refractive index, surface roughness, surface morphology, chemical bonding and microstructure.

The result showed that the sputtering pressure has an imperative effect on the properties of magnetron sputtered thin films. Good quality and near stochiometric silicon nitride thin films with minimum surface value of 1.2 $\mathrm{nm}$, at growth rate $7.03 \mathrm{~nm} / \mathrm{min}$ were obtained under 3 mTorr sputtering pressure.

The refractive index, surface roughness, excess silicon content and stress of deposited thin films increased linearly with the sputtering pressure. However, an optimum sputtering pressure value was observed during the characterization for growth rate. The growth rate was increased until that optimum value and then started decreasing due to back diffusion and scattering effect.

As a future work, the stoichiometry of silicon nitride thin films produced by RF magnetron sputtering can be adjusted by bleeding nitrogen gas during the deposition but this could affect the growth rate of thin films.

\section{ACKNOWLEDGEMENTS}

The authors wish to thank the center for graduate studies, Universiti Tun Hussein Onn Malaysia (UTHM) and Ministry of Education, Malaysia for supporting of this work through FRGS vot 1048. 


\section{REFERENCES}

[1] Xu, G.; Jin, P.; Tazawa, M.; Yoshimura, K. Thin Solid Films. 425 (2003) 196.

[2] Ma, T.P. IEEE Trans. Electron Dev. 45 (1998) 680

[3] Seiffe, J.; Gautero, L.; Hofmann, M.; Rentsch, J.; Preu, R.; Weber, S.; Eichel, R. A. J. Appl. Phys. 109 (2011) 034105.

[4] Spinelli, P.; Hebbink, M.; van Lare C.; Verschuuren, M.; de Waele, R.; Polman,A. Optical Society of America (2010).

[5] Lin, P. T.; Singh, V.; Kimerling, L.; Agarwal, A. M. Appl. Phys Lett. 102 (2013) 251121

[6] Shi S.; Wang X.; Xu C.; Yuan J.; Fang J.; Jiang S.; Liu S. (ICEPT 2013) IEEE.

[7] Wu, P. H.; Lin, I. K.; Yan, H. Y.; Ou, K. S.; Chen, K. S.; Zhang, X. Sens. Actuator B-Phys. 168 (2011) 117

[8] Sousa, R.; Ribeiro, J. F.; Sousa, J. A.; Montenegro, R. T.; Goncalves, L. M.; Correia, J. H. (2013)
[9] Mousinho, A. P.; Mansano, R. D.; Zambom L. S.; Passaro A. J. Phys. Conf. Ser. 370 (2012) 012015

[10] Liu, Y.; Lin, I.; Zhang, X. Mater. Sci. Eng. A. 489 (2008) 294.

[11] Tiwari, R.; Chandra, S.; Adv. Mater. Res. 254 (2011). 187.

[12] Sandland, J.G. PhD. Thesis M.I.T. 2004.

[13] Smietana, M.; Brabant, D.; Bock,W. J.; Mikulic, P.; Eftimov, T. J. Lightwave Technol. 30 (2012) 1185.

[14] Chapman, B.; Glow Discharge Processes: Sputtering and Plasma Etching. John Wiley \& Sons, Inc. (1980).

[15] Hirohata, Y.; Shimamoto, N.; Hino, T.; Yamashima, T.; Yabe, K.. Thin Solid Films 253 (1994) 425.

[16] Signore, M. A.; Sytchkova, A.; Dimaio, D.; Cappello, A.; Rizzo, A. Opt. Mater. 234 (2012) 632.

[17] Rouchon, D.; Rochat, N.; Gustavo, F.; Chabli, A.; Renault, O.; Besson, P. Surf. Interface Anal. 34 (2002) 445.

[18] Artieda, A.; Barbieri, M.; Sandu, C. S.; Muralt, P. J. Appl. Phys. 105 (2009) 024504.

[19] Lee, H. C.; Kim, G. H.; Hong, S. K.; Lee, K. Y.; Yong, Y. J.; Chun, C. H.; Lee, J. Y. (1995). Thin solid films 261 (1995) 148. 